\title{
Electrochemical corrosion behavior of silver doped tricalcium phosphate coatings on magnesium for biomedical application
}

\author{
Ruben Kotoka ${ }^{1 *}$, Nana Kwame Yamoah ${ }^{1}$, Kwadwo Mensah-Darkwa ${ }^{2}$, Timothy Moses ${ }^{3}$ and \\ Dhananjay Kumar ${ }^{1}$ \\ ${ }^{1}$ NSF Engineering Research Center for Revolutionizing Metallic Biomaterials, North Carolina \\ A\&T State University, Greensboro, NC 27411 \\ ${ }^{2}$ Department of Material Engineering, Kwame Nkrumah University Science and Technology, \\ Kumasi, Ghana \\ ${ }^{3}$ Biocompatibility and Tissue Regeneration Laboratory, Clemson University, Laurens, SC 29632
}

*Corresponding author. E-mail address: rbkotoka@gmail.com (R. Kotoka).

\begin{abstract}
This paper investigates the growth, characterization and electrochemical corrosion properties of tricalcium phosphate (TCP) doped with 0 wt. $\%, 1$ wt. $\%, 5$ wt. $\%$ and $10 \mathrm{wt} . \%$ of silver coatings deposited on magnesium substrate using pulsed laser deposition (PLD). The phase and morphological properties of the coatings were analyzed using X-ray diffraction (XRD) and scanning electron microscopy (SEM) respectively. The SEM images showed that increasing the percentage of Ag dopant reduces the size of droplets formed during the deposition process. The corrosion protection behavior of the coated samples were evaluated using potentiodynamic polarization (PD) and electrochemical impedance spectroscopy (EIS). The corrosion test were performed in Hanks' Balanced Salt Solution and 0.9 wt. \% saline solution using three electrode electrochemical cell. The results showed that TCP coated magnesium exhibits a much superior stability and lower corrosion rate compared to bare $\mathrm{Mg}$. It was observed that increasing the mass of the Ag dopant increases the corrosion protection, but $10 \% \mathrm{Ag}$ doping in TCP reduces the corrosion protection behavior. In conclusion, we have developed TCP and TCP doped with $1 \%$, $5 \%$ and $10 \% \mathrm{Ag}$ coating with tunable corrosion protection efficiency.
\end{abstract}

Keywords: Tricalcium phosphate coatings; biodegradable magnesium; electrochemical corrosion properties; porosity; pulsed laser deposition (PLD) 


\section{INTRODUCTION}

Implant devices such as bone fixation plates, stents, screws, and wires are commonly used to provide structural support and/or to assist in the healing process after surgical procedures, such as orthopedic, craniofacial or angioplasty interventions. Presently, these implant devices are made from bioinert material such as titanium alloys, stainless steels and cobalt-chrome alloys [15]. However, additional surgeries are required to remove these devices once the healing process is complete [1, 6]. This procedure increases cost and in some cases leads to patient morbidity [7]. In recent years, biodegradable metallic implants are beginning to change the paradigm of using only highly corrosion-resistant metallic implants for surgical procedures [8, 9]. These biodegradable implants naturally dissolve in vivo after the healing process is complete and may not require second surgery. Even though polymers such as polyglycolic acid (PGA), polylactic acid (PLA), polydioxanone (PDS) have been widely used as biodegradable materials for certain applications, they lack the mechanical strength required for load bearing applications [10]. Biodegradable metals have more desirable mechanical properties due to their relatively high strength and fracture toughness [11-13]. Magnesium has shown great promise in this regard not only because of its high tensile strength and a Young's modulus which is comparable to that of natural bone, but its degradation products are easily metabolized by the body [8, 14].

Although, magnesium is a great candidate for uses in orthopedic implant applications due to their biocompatibility, mechanical properties and degradability, they are susceptible to accelerated degradation in aqueous environment [15]. Recent research efforts have been geared towards the control of the degradation rate of magnesium by various surface modification processes and alloying with corrosion resistant elements [16-18]. Despite the recent progress in the effort to control the degradation rate, it is also important to consider the processes that takes place between biodegradable implants and their surrounding tissues. Interface properties and interfacial processes between implants and their surrounding tissues in most cases determine the success of implants. Among the interfacial processes osseointegration and bacterial infection have been identified as the most pertinent in developing new materials and devices for implant applications $[19,20]$. Over the last two decades several research have dedicated a lot of effort to improve the osseointegration of implants by altering the chemical composition at the implant/surrounding tissue interface. The most reported materials commonly used are tricalcium phosphate and hydroxyapatite [21-24]. In addition to accelerating bone growth, tricalcium 
phosphate can improve the corrosion properties of magnesium. Zhang et al (2009) reported that the corrosion rate of magnesium implants can be adequately controlled by covering them with well-adjusted thick apatite coatings [25]. Song et al (2009) studied the transformation of $\beta$ tricalcium phosphate into uniform hydroxyapatite coating after immersion in $1 \mathrm{M} \mathrm{NaOH}$ solution. Their results showed a high improvement in the corrosion resistance and bioactivity on the surface of AZ91D magnesium alloy immersed in simulated body fluid (SBF) [26].

Another major risk associated with medical implant procedures is their high rate of infection at the implant-bone interface [19]. Silver coatings have been reported to exhibit excellent antibacterial properties capable of addressing bacterial colonization on implants and other nosocomial infections during surgical procedures [27]. The efficiency of silver coatings in controlling bacteria colonizing around an implant is dependent on the balanced of activities between the silver cation which kill bacteria and the concentration of silver ions released from the coating. A very high concentration of silver cations released from the coating can be toxic to cells [28]. Silver coating on magnesium will form a galvanic pair which will accelerate corrosion of the substrate. Therefore doping TCP with silver can control the galvanic corrosion of magnesium, while enhancing the osseointegration properties. Also the right balanced of silver is required to maintain the corrosion protection of TCP, as well as control the toxicity effect due to high concentrations of silver. Won-Hoon et. al. (2007) investigated the antibacterial properties of Ag containing calcium phosphate coatings formed by micro-arc oxidation on titanium implants [29]. Their results showed that, while the coatings with a high content of Ag were cytotoxic, the calcium phosphate coatings obtained in the low $\mathrm{Ag}$ concentration electrolyte exhibited in vitro antibacterial activity but no cytotoxicity [29]. Although a lot of work has gone into improving the osseointegration and antibacterial properties of magnesium using TCP and silver respectively [30-32], there is the need to comprehensively evaluate the effect of Ag doped TCP coating on the corrosion properties of magnesium in simulated body fluids.

In the present work, we report the effects of Ag doping on the structure and corrosion properties of TCP coating developed on biodegradable Mg disk. The effect of different doping concentration on the microstructure and porosity were evaluated. The corrosion properties of the coatings were evaluated in Hanks' Balanced Salt Solution (HBSS) and physiological saline solution $(0.9$ wt. $\% \mathrm{NaCl})$. 


\section{EXPERIMENT}

\subsection{Material Fabrication}

The $\beta$-TCP doped with 0 wt. $\%, 1$ wt. $\%, 5$ wt. $\%$ and 10 wt. $\%$ of silver coatings were deposited from in-house sintered target. The pure $\beta$-TCP (0 wt. \% doped Ag) target was prepared by cold pressing $\beta$-TCP powder (Sigma-Aldrich, USA) at $6 \times 10^{6} \mathrm{~N} / \mathrm{m}^{2}$ pressure followed by sintering at $1250{ }^{\circ} \mathrm{C}$ for $9 \mathrm{~h}$. While the $1 \mathrm{wt} . \%, 5 \mathrm{wt} . \%$ and $10 \mathrm{wt}$. \% Ag doped $\beta$-TCP targets were prepared by mixing the pure $\beta$-TCP powder with the different weight percent of silver nanoparticles (Sigma-Aldrich, USA) followed by sintered at $850{ }^{\circ} \mathrm{C}$ for $9 \mathrm{~h}$. The $\beta$-TCP doped with different compositions of silver coatings were deposited using a $\mathrm{KrF}$ excimer laser (Lambda Physik COMPex, $\lambda=248 \mathrm{~nm}$ and pulse duration of $20 \mathrm{~ns}$ ). The laser was operated at a pulse rate of $10 \mathrm{~Hz}$ with energy density of $2 \mathrm{~J} / \mathrm{cm}^{2}$. The $\beta$-TCP doped with different weight compositions of silver coatings were deposited on $\mathrm{Mg}$ substrates at room temperature in vacuum in excess to $5 \times$ $10^{-6}$ Torr $\left(0.667 \times 10^{-3} \mathrm{~Pa}\right)$. The deposition rate of the system was calibrated and the thicknesses of the $\beta$-TCP doped with different compositions of silver coatings were controlled at $1 \mu \mathrm{m}$. Polished high purity $99.97 \%$ Mg (Goodfellow, Germany) disks were used as substrates. The magnesium substrates were polished progressively with $\mathrm{SiC}$ paper from grade \#400 up to grade \#1200 using isopropyl alcohol as the lubrication fluid. The polished samples were etched in nital (methanol:nitric acid in the ratio $2: 1$ ).

\subsection{Thin Film Characterization}

The surface morphology and phase analysis of the films were investigated using Hitachi SU8000 scanning electron microscope (SEM) and Bruker D8 tool X-ray diffractometer (XRD) respectively. The SEM was operated at high magnification with a voltage of $2 \mathrm{kV}$ and probe current of $5 \mathrm{~mA}$. The XRD experiments were performed using a locked-coupled scan with a scanning range (diffraction angle, $2 \theta$ ) set between 20 and $80^{\circ}$. The $\mu$-XRF elemental analysis and mapping were conducted with $50 \mu \mathrm{m}$ XGT capillary diameter with X-ray tube voltage and current of $50 \mathrm{kV}$ and $1.000 \mathrm{~mA}$ respectively. The elemental analyses were conducted by selecting an array of 5 X 5 points ( 25 points) across the surface of the targets and coatings.

\subsection{Electrochemical Test}

DC polarization studies were carried out using a Gamry R600 Potentiostat (Gamry 
Instruments). All DC polarization measurements were performed in Hanks' Balanced Salt Solution (HBSS) and physiological saline solution $(0.9 \mathrm{wt} \% \mathrm{NaCl})$ at room temperature. The scan rate was set at $0.5 \mathrm{mV} / \mathrm{s}$ spanning a scan range of $\pm 0.3 \mathrm{~V}$ vs open circuit potential $\left(\mathrm{E}_{\mathrm{oc}}\right)$. A Gamry para cell with a standard three-electrode configuration consisting of a standard $\mathrm{Ag} / \mathrm{AgCl}$ electrode and platinum were used as the reference and counter electrodes respectively, while the sample acted as the working electrode. The working electrode was connected with a copper wire on the backside and installed in customized Teflon assembly and exposed on the solution side to about $0.283 \mathrm{~cm}^{2}$ working area. Three replicate samples were used for each test condition. Prior to the corrosion measurements, the $\mathrm{pH}$ of the solutions were maintained at 7.

EIS measurements were performed at room temperature in the frequency range of 0.1 to $10^{5} \mathrm{~Hz}$ using a Gamry R600 potentiostat at the open circuit potential with a sinusoidal voltage of amplitude $10 \mathrm{mV}$. The resulting sinusoidal current was measured at the counter electrode. The EIS measurements were performed in Hanks' Balanced Salt Solution (HBSS) and physiological saline solution $(0.9 \mathrm{wt} \% \mathrm{NaCl})$ at room temperature. The samples were immersed in the test solution for $24 \mathrm{~h}$, while the EIS data was collected at each hr. Three replicate samples were used for each test condition. The analyses were performed using Echem Analyst commercial software developed by Gamry.

\subsection{Electrochemical Corrosion Analyses}

From the electrochemical parameters: corrosion current density $\left(i_{\text {corr }}\right)$, anodic tafel slope $\left(\beta_{\mathrm{a}}\right)$ and cathodic tafel slope $\left(\beta_{\mathrm{c}}\right)$, polarization resistance $\left(\mathrm{R}_{\mathrm{P}}\right)$ was calculated according to equation (6) [33].

$$
R_{P}=\frac{\beta_{a} \cdot \beta_{c}}{2.3 \cdot\left(\beta_{a}+\beta_{c}\right) \cdot i_{c o r r}}
$$

The protection properties of the coatings were evaluated using protection eficiency (PE) relationship. The coatings' protection efficiency were estimated using equation (2) [34]:

$$
P E(\%)=\left(\frac{i_{c o r r}-i_{c o r r}^{\prime}}{i_{c o r r}}\right) \times 100
$$

where $i_{\text {corr }}$ and $i_{\text {corr }}^{\prime}$ are the corrosion current densities of the uncoated and coated $\mathrm{Mg}$ respectively. 
The porosity of the protective coatings were estimated using the following expression [34].

$$
P=\left(\frac{R_{p s}}{R_{p}}\right) \times 10^{-\left(\Delta E_{c o r r} / b_{A}\right)}
$$

where $\mathrm{P}$ is the total coating porosity rate, $\mathrm{R}_{\mathrm{ps}}$ is the polarization resistance of the uncoated $\mathrm{Mg}$ disk, $\mathrm{R}_{\mathrm{p}}$ is the polarization resistance of the coated $\mathrm{MgE}$ corr is the difference potential between the corrosion potentials of the coated substrate and uncoated substrate, and $b_{\mathrm{A}}$ is the anodic Tafel slope for the uncoated substrate.

\section{RESULTS AND DISCUSSION}

\subsection{Structural, Compositional and Microstructure Characterization}

In the phase diagram of the $\mathrm{CaO}-\mathrm{P}_{2} \mathrm{O}_{5}$ system, three polymorphs corresponding to $\mathrm{Ca}_{3}\left(\mathrm{PO}_{4}\right)_{2}$ (TCP) are known: $\beta$-TCP, $\alpha$-TCP and $\alpha^{\prime}$-TCP [35]. The $\beta$-TCP phase is stable at room temperature and transforms to $\alpha$-TCP at temperatures between $1125{ }^{\circ} \mathrm{C}$ to $1250{ }^{\circ} \mathrm{C}[35,36]$. The $\alpha$-TCP phase may be retained at room temperature in a metastable state. The $\alpha^{\prime}$-TCP phase exists at temperatures above $1430{ }^{\circ} \mathrm{C}$ and reverts instantaneously to $\alpha$-TCP on cooling below the transition temperature [35]. The pure TCP target used in this study was sintered at $1250{ }^{\circ} \mathrm{C}$ because it has been reported that when the temperature reached $1250{ }^{\circ} \mathrm{C}$ the open porosity tends to stabilize accompanied by a significant decrease in the densification [37]. This temperature was also selected in order to take advantage of the excellent corrosion properties, bioactive response and osseointegration properties of $\beta$-TCP $[31,38,39]$. Since the sintering temperature of the $\beta$ TCP target was close to $\alpha$-TCP transformation temperature, XRD analysis was conducted to confirm the phase. The XRD patterns of the sintered targets are shown in Fig. 1 a. The diffraction patterns were compared with JCPDS file 009-0169. The XRD pattern confirmed that $\beta$-TCP was formed after the sintering process. As shown in Fig. 1 a, all the sintered targets showed diffraction pattern of $\beta$-TCP very similar to what was been reported by Banerjee and coworkers [40]. This shows that silver doping did not change the crystallization properties of the $\beta-\mathrm{TCP}$ targets. However, an additional peak is present in the XRD pattern of $\beta$-TCP doped with Ag samples, but not in the XRD pattern of pure $\beta$-TCP target. This peak can be found in the inset in

Fig. 1 a. The inset shows a short range scan (20) between $36040^{\circ}$. The additional peak featured in the inset shows a peak of Ag (111), as referred in JCPDS card (reference PDF card 
00-004-0783). This verification was important because the sintering was conducted at $850{ }^{\circ} \mathrm{C}$ which is very close to the melting point of silver $\left(\sim 960^{\circ} \mathrm{C}\right)$.

A comparison between the XRD patterns of pure $\beta$-TCP target $(0 \mathrm{wt} . \%$ of Ag) and pure $\beta$-TCP coating ( 0 wt. $\%$ of $\mathrm{Ag}$ ) on Mg substrate is shown in Fig. 1 b. The XRD pattern of the pure $\beta$-TCP coating on $\mathrm{Mg}$ substrate shows peaks corresponding to a hexagonal phase of polycrystalline Mg (JCPDS file 035-0821) with a lattice parameters of a and c equal to 0.32094 $\mathrm{nm}$ and $0.52112 \mathrm{~nm}$, respectively. The pure $\beta$-TCP coating on the $\mathrm{Mg}$ substrate did not show any peaks corresponding to the $\beta$-TCP peaks. This may be due to the intensity of the $\mathrm{Mg}$ peaks or the coatings were amorphous. Zeng et. al. (2000) and Mroz et. al. (2009) investigated the structural properties of pulsed laser deposited calcium phosphate coatings on Ti substrates and their results showed TCP peaks with Ti peaks $[41,42]$. After further investigation of the crystallinity of the coatings around specific TCP peak positions no peaks were observed, it was therefore concluded that the coatings were amorphous.

The results of the elemental analysis of the target and coatings are shown in table 1 and 2 respectively. TCP doped with 0 wt. $\%, 1 \mathrm{wt} \%, 5 \mathrm{wt} \%$ and $10 \mathrm{wt}$ \% $\mathrm{Ag}$ targets have calcium to phosphorus ratios $(\mathrm{Ca} / \mathrm{P})$ of $1.48,1.55,1.31$ and 1.25 respectively. While, TCP doped with 0 wt. $\%, 1 \mathrm{wt} \%, 5 \mathrm{wt} \%$ and 10 wt. \% Ag coatings on Mg substrates have calcium to phosphorus ratios $(\mathrm{Ca} / \mathrm{P})$ of $1.64,1.57,1.56$ and 1.44 respectively. It was observed that $\mathrm{Ca} / \mathrm{P}$ ratios decreases with increasing Ag doping content. Prem et. al. suggested that this may be due to the formation of amorphous calcium phosphate and the incorporation of lower ionic radii of metal (Ag) sites in the $\beta$-TCP structure [43]. Although the elemental analyses suggest that the Ca-P phase may have be altered after sintering, the XRD results confirm that all the sintered targets have tricalcium phosphate phase with peaks of $\mathrm{Ag}$. The range of $\mathrm{Ca} / \mathrm{P}$ ratios reported for both sintered targets and coatings are the most common range $(1.00-1.67)$ used for orthopedic devices [44].

Fig. 2 shows the surface morphology of uncoated $\mathrm{Mg}$ and TCP doped with $0 \mathrm{wt}$ \%, $1 \mathrm{wt}$ $\%, 5$ wt \% and 10 wt. \% Ag coating on Mg (Fig. 2 a, b, c, d and e respectively) as observed by SEM. All the coatings developed were compact without obvious cracks existence, and the surface morphologies of the films were typical for PLD grown films exhibiting droplets of different size on uniformly coated disk. However, the micrographs clearly show that the added amounts of Ag exert a strong influence on the overall morphological aspects. The size of the droplet found in the pure TCP may be "chunks" deposited during the laser ablation of the TCP 
target. The TCP sintered at $1250{ }^{\circ} \mathrm{C}$ is reported to be hard and brittle which makes it more susceptible to deposit "chunks" during deposition [45]. It has been reported that doping TCP with increasing the weight composition of silver reduces the density of the sintered material [46]. Zeng et al., (1999) showed that TCP coatings produced with the low-density targets are generally smooth with some spherical particles present with no pores observed, while TCP coatings produced with the high-density target appeared to be rougher with pores and both spherical and irregular particles [42]. Contrary to their observation, there is an increase in the area of coverage by the droplets when the composition of $\mathrm{Ag}$ is increased to $10 \mathrm{wt}$ \%. This suggest that increasing the concentration of the dopant above a $5 \mathrm{wt}$. \% will adversely affect the area of coverage of droplets.

Fig. 3 shows the cross-section micrograph of the TCP doped with 0 wt. $\%, 1 \mathrm{wt} \%, 5 \mathrm{wt}$ $\%$ and 10 wt. \% Ag coating on Mg (Fig. 3 a, b, c, d and e respectively) as observed in SEM. From the cross-sectional images it is evident that the coatings are very dense without any visible micro-cracks and pinholes. Although the film thicknesses are uniformly consistent over the surface of each sample as can be observed from fig. 3, but the thicknesses are different between samples. The thicknesses measured using Image-pro Plus 6 software show that the thicknesses for TCP doped with 0 wt. $\%, 1 \mathrm{wt} \%, 5 \mathrm{wt} \%$ and 10 wt. $\%$ Ag were $1.952 \pm 0.051 \mu \mathrm{m}, 1.437 \pm$ $0.047 \mu \mathrm{m}, 1.678 \pm 0.10 \mu \mathrm{m}$ and $1.935 \pm 0.1 \mu \mathrm{m}$ respectively.

\subsection{Electrochemical Corrosion Characterization}

Magnesium degrades in aqueous media through an electrochemical reaction which produces magnesium hydroxide $\mathrm{Mg}(\mathrm{OH})_{2}$ and hydrogen gas $\left(\mathrm{H}_{2}\right)$ is evolved [47, 48]. The overall corrosion reaction of magnesium in aqueous media is given by equation (1):

$$
M g_{(s)}+2 H_{2} O_{(a q)} \square \mathrm{Mg}(\mathrm{OH})_{2(s)}+H_{2(g)}
$$

Contributing half-cell reactions are:

$$
\begin{gathered}
M g_{(s)} \square \quad M g_{(a q)}^{2+}+2 e^{-} \text {(anodic reaction) } \\
2 \mathrm{H}_{2} \mathrm{O}_{(a q)}+2 e^{-} \square \quad \mathrm{H}_{2(\mathrm{~g})}+2 \mathrm{OH}_{(a q)}^{-} \text {(cathodic reaction) }
\end{gathered}
$$




$$
\mathrm{Mg}_{(\mathrm{aq})}^{2+}+2 \mathrm{OH}_{(\mathrm{aq})}^{-} \mathrm{Mg}(\mathrm{OH})_{2(s)} \text { (product formation) }
$$

In the presence of chloride ions the magnesium hydroxide dissolves by reacting into the soluble salt, $\mathrm{MgCl}_{2}$.

$$
\mathrm{Mg}(\mathrm{OH})_{2(s)}+2 \mathrm{Cl}_{(a q)}^{-} \square \quad \mathrm{MgCl}_{2(s)}+2 \mathrm{OH}_{(a q)}^{-}
$$

In a typical corrosion of magnesium in simulated body fluid, the corrosion product $\mathrm{Mg}(\mathrm{OH})_{2}$ accrues as a secondary corrosion protective layer. This secondary protective layer increases the corrosion resistance over time. If the corrosive medium contains any chlorides, the hydroxide will be converted to a more soluble magnesium chloride $\left(\mathrm{MgCl}_{2}\right)$ rather than magnesium hydroxide. Therefore, in high concentration of chloride ions magnesium becomes susceptible to fast degradation rate. In simulated body fluids such as phosphate buffer saline (PBS) and Hanks' Balanced Salt Solution solution (HBSS) there is formation of hydroxyapatite on the surface due to consumption of $\mathrm{Ca}^{2+}$ and $\mathrm{PO}_{4}{ }^{3-}[49,50]$. These hydroxyapatite compounds can significantly increase the corrosion resistant of $\mathrm{Mg}$, hence reducing its corrosion rate.

\subsubsection{Polarization}

The significance of the DC polarization measurement was to evaluate the protection properties of the coatings by monitoring the degradation of the $\mathrm{Mg}$ substrate. The results of the DC polarization study of the uncoated $\mathrm{Mg}$ and $\mathrm{Ag}$ doped TCP coatings on Mg substrate immersed in HBSS and physiological saline solution for $2 \mathrm{~h}$ are shown in Figs $4 \mathrm{a}$ and $\mathrm{b}$ respectively. The corrosion current density $\left(\mathrm{i}_{\text {corr }}\right)$ and corrosion potential $\left(\mathrm{E}_{\text {corr }}\right)$ extracted from the polarization curves are shown in Table 3. Corrosion current density ( $\left.\mathrm{i}_{\text {corr }}\right)$ is directly proportional to the corrosion rate of the system (coating/substrate), therefore the $\mathrm{i}_{\text {corr }}$ results obtained in the study represents the degradation properties of the substrate which is being protected by the coating [51]. As the corrosion potential $\left(\mathrm{E}_{\text {corr }}\right.$ ) becomes more positive, the rates of anodic reactions increase and the rates of cathodic reactions decrease. From the results it is evident that the magnesium substrate coated with Ag doped TCP have higher corrosion potential compared to the bare magnesium substrate indicating the significant effect of the coating on the corrosion behavior of Mg. As can be observed in Fig. 4, by increasing the doping percentage of $\mathrm{Ag}$ in TCP coating on Mg substrate the corrosion potential moves in the positive direction. This suggests that increasing the doping concentration increases the density of the coatings and 
promotes the formation of a passive layer which decreases the cathodic reaction.

The average current density of the TCP doped with $0 \mathrm{wt} . \%, 1 \mathrm{wt} \%, 5 \mathrm{wt} . \%$ and $10 \mathrm{wt}$. $\%$ immersed in HBSS is $0.351 \mu \mathrm{A} / \mathrm{cm}^{2}, 0.013 \mu \mathrm{A} / \mathrm{cm}^{2}, 0.006 \mu \mathrm{A} / \mathrm{cm}^{2}$ and $0.132 \mu \mathrm{A} / \mathrm{cm}^{2}$ respectively compared to $3.251 \mu \mathrm{A} / \mathrm{cm}^{2}$ of bare $\mathrm{Mg}$ substrate. A similar trend is found in the samples immersed in physiological saline solution with corrosion current densities of TCP doped with 0 wt. $\%, 1$ wt. $\%, 5$ wt. $\%$ and 10 wt. $\%$ being $3.574 \mu \mathrm{A} / \mathrm{cm}^{2}, 0.281 \mu \mathrm{A} / \mathrm{cm}^{2}, 0.183 \mu \mathrm{A} / \mathrm{cm}^{2}$ and $2.462 \mu \mathrm{A} / \mathrm{cm}^{2}$ respectively compared to $4.488 \mu \mathrm{A} / \mathrm{cm}^{2}$ of bare Mg substrate. Since corrosion current density is directly proportional to the corrosion rate [51], these results show that there is 1 order decrease in the corrosion rate of $\mathrm{Mg}$ coated with TCP immersed in HBSS, while the corrosion rate of $\mathrm{Mg}$ is 1.15 times less in physiological saline solution. Adding $5 \mathrm{wt}$ \% $\mathrm{Ag}$ doped TCP coating on Mg decreases the corrosion rate to 1and 3 orders in physiological saline solution and HBSS respectively.

Also from the electrochemical parameters, the polarization resistance $\left(R_{P}\right)$ of the samples were calculated using equation (1). The results of the polarization resistance have been outlined in table 3. The results show that there is about 14 times increase in polarization resistance of TCP coating on $\mathrm{Mg}$ substrate immersed in HBSS compared to bare $\mathrm{Mg}$, while in physiological saline solution there is only 3 times increase. Also, increasing the concentration of Ag improves the polarization resistance of the $\mathrm{Mg}$ substrate in both media. However, there is a drop in polarization resistance when the concentration of $\mathrm{Ag}$ doping is increased to $10 \mathrm{wt}$. \%. This suggests that by increasing the concentration of $\mathrm{Ag}$ to $10 \mathrm{wt}$. \% the $\mathrm{Mg}$ substrate becomes susceptible to galvanic corrosion. The results also shows about 10 time increase in the polarization resistance of the coatings immersed in HBSS compared to those immersed in physiological solution. This is a clear evidence that increasing the concentration of $\mathrm{Cl}^{-}$ions increases the corrosion rate.

Fig. 5 shows the protection efficiency of TCP doped with 0 wt. \%, 1 wt. \%, 5 wt. \% and 10 wt. \% Ag coatings on Mg substrate immersed in HBSS for $24 \mathrm{hrs}$. The protection efficiency of the samples were computed using equation (2). The results clearly show that the corrosion protection property of the coatings degrade over time and the rate of degradation depends on the concentration of Ag. TCP doped with 0 wt. \% and 10 wt. \% Ag coating on Mg substrates showed the least corrosion protection over time. It is evident from the results that TCP doped with $10 \mathrm{wt}$. $\% \mathrm{Ag}$ shows improved corrosion behavior for $4 \mathrm{~h}$ compared to pure TCP, but after $8 \mathrm{~h}$ the 
protection efficiency of TCP doped with wt. $10 \% \mathrm{Ag}$ drops significantly until there is no protection from the coating after $185 \mathrm{~h}$. At $24 \mathrm{~h}$, the pure TCP coating has protection efficiency about $10 \%$. In contrast, TCP doped with 1 wt. \% and 5 wt. \% Ag have about $80 \%$ and $95 \%$ protection efficiency after $24 \mathrm{~h}$ respectively. Since the differences in the adhesion between the coatings and the $\mathrm{Mg}$ substrate are expected to be minimal, the major contribution of the decline in the protection efficiency can be attributed to differences in porosity due to doping. In the case of TCP doped with 10 wt. \% Ag coating on $\mathrm{Mg}$, galvanic corrosion may have also contributed to the fast decline in corrosion protection.

\subsubsection{Electrochemical Impedance Spectroscopy (EIS)}

EIS measurements were conducted to evaluate the corrosion mechanism and the contribution of the individual layers of the coating/Mg substrate system to the corrosion process. The results of the electrochemical impedance spectroscopy analyses of the uncoated $\mathrm{Mg}$, TCP doped with 0 wt. $\%, 1$ wt. $\%, 5$ wt. $\%$ and 10 wt. \% Ag coatings on Mg substrate immersed in HBSS and physiological saline solution are shown in Figs. 6 a and b respectively. The results from the EIS test confirms the observations made from the potentiodynamic polarization test. Increasing the concentration of the Ag dopants up to $5 \mathrm{wt}$ \% increases the corrosion resistance (impedance). However, there is a decrease in corrosion resistance (impedance) when the $\mathrm{Ag}$ concentration is increased to $10 \%$ possibly as a result of galvanic corrosion. From the results it is evident that there is 10 times differences in corrosion resistance (impedance) between the coatings immersed in physiological saline solution compared to HBSS. The resistance (impedance) of TCP doped with 10 wt. \% Ag coatings is lower than pure TCP in physiological saline solution compared to HBSS. This may be due to the reaction between the ions and the susceptibility of TCP doped with $10 \mathrm{wt}$ \% Ag to galvanic corrosion, but the corrosion of pure TCP is driven through the pores in the coating.

\subsubsection{Equivalent Circuit Modeling (ECM)}

The data from the EIS were further analyzed using equivalent circuit modeling technique. In equivalent circuit modeling, the response of the electrochemical system was modeled by a network of passive circuit elements which mimics the electrochemical properties of the corroding system. The electrical circuit developed for bulk magnesium and TCP coatings are 
shown in Fig. 7 (a) and (b) respectively. The oxide layer was added to the substrate to mimic the product of polishing and etching on the magnesium surface prior to coating. The analyses were performed using ZSimp and ECHEM analyst commercial software developed by Gamry.

The total polarization resistance $\left(\mathrm{R}_{\mathrm{p}}\right)$ includes the resistance of the coating including the pores and the resistance of the interface between the defective site and the substrate, i.e., $R_{0}, R_{\text {coat }}$ and $R_{c t}$. The values of $R_{0}, R_{\text {coat }}$ and $R_{c t}$ were obtained according to the equivalent circuit at different immersion time over a period of $24 \mathrm{~h}$. The experimental results were interpreted on the basis of equivalent circuit using a suitable fitting procedure. The equivalent electrical circuit consists of the following elements; $R_{s}$ corresponds to the solution resistance of the test electrolyte between the working electrode and the reference electrode, and $\mathrm{C}_{\text {coat }}$ is the capacitance of the multilayer coating including pores in the outer layer coating. $\mathrm{R}_{\text {coat }}$ is the pore resistance resulting from the formation of ionic conduction paths across the coating. $\mathrm{C}_{\text {coat }}$ is the capacitance of the multilayer coating within the defect and $R_{c t}$ the charge transfer resistance of the substrate/coating interface. During the fitting process, the capacitance values were represented by general diffusion, which is defined as a constant phase element (CPE) that accounts for deviations from the ideal dielectric behavior related to surface inhomogeneity [52].

A comparison of the polarization resistance of pure TCP coating on $\mathrm{Mg}$ substrate immersed in HBSS and physiological saline solution over a period of $24 \mathrm{~h}$ is shown in Fig. 8. It is evident from the results that the polarization resistance of the pure TCP coating immersed in HBSS increases over the $24 \mathrm{~h}$ period. This suggests that there is formation of corrosion product on the coating/ $\mathrm{Mg}$ substrate interface. This products acts as an additional layer of protection, therefore increasing the corrosion resistance. In case of physiological saline solution, the protective layer $\mathrm{Mg}(\mathrm{OH})_{2}$ is converted to $\mathrm{MgCl}_{2}$ that dissolves in the solution exposing the surface for further corrosion.

The porosity of protective coating is an important parameter for determining the quality of the coating. For porous coatings, the pores provide direct path between the corrosive media and the substrate leading to localized corrosion of the substrate. This form of corrosion has been reported to accelerate the corrosion of the magnesium substrate, leading to hydrogen embrittlement [47]. The porosity of the samples were computed using equation (3) and the result of the porosity analyses of the various coating immersed in HBSS and physiological saline solution are shown in Figs. 9 a and b respectively. The results of the porosity analyses show 
significant difference the porosity in HBSS and physiological saline solution. The coatings immersed in physiological solution show a higher initial porosity, which suggest that the coating offer minimal resistance to the flow of $\mathrm{Cl}^{-}$ions. It is evident from the results that TCP doped with 5\% Ag experiences the less degradation over $24 \mathrm{~h}$ in both HBSS and physiological saline solution.

\subsection{Microstructural Analysis of the After Corrosion}

Fig. 10 show the microstructural analyses conducted on the bare Mg substrate, TCP doped with 0 wt. $\%, 1$ wt. $\%, 5$ wt. $\%$ and 10 wt. $\%$ Ag coatings on $\mathrm{Mg}$ substrates after $24 \mathrm{~h}$ of immersion in physiological saline solution. From the SEM micrographs, it is evident that TCP doped with $5 \% \mathrm{Ag}$ experienced the least corrosion. This confirms the earlier observations made from the potentiodynamic polarization and electrochemical impedance spectroscopy measurements. To evaluate the extent of degradation after immersing the pure TCP coating on Mg substrate in physiological saline solution for $24 \mathrm{~h} \mu$-XRF elemental mapping was conducted. The result of the elemental mapping is shown in figure 11. The $\mu$-XRF elemental mapping shows the degradation of the coating over a larger area compared to the SEM images. From the $\mu$-XRF elemental mapping it is evident that the coating is completely disintegrated after the $24 \mathrm{~h}$ period. The calcium and phosphorous map shows the area of coverage of the coating after the corrosion process. The area of coverage can be estimated as $70 \%$ which is close to the results obtained by the porosity analysis.

\section{CONCLUSIONS}

In-house sintered TCP doped with different concentration of $\mathrm{Ag}(0$ wt. $\%, 1$ wt. $\%, 5$ wt. $\%$ and $10 \mathrm{wt}$. \%) target was deposited on pure Mg substrate using pulsed laser deposition (PLD). The coatings were characterized and their electrochemical corrosion properties analyzed. The results presented show addition of the Ag dopant improved the corrosion protection properties of the coating, and the corrosion resistance increases with increasing doping concentration. However, TCP doped with 10 wt. \% of Ag showed a lower corrosion resistance which may be due to galvanic coupling between the $\mathrm{Mg}$ substrate and the $\mathrm{Ag}$ nanoparticle. The coatings also provided lower corrosion resistance in physiological saline solution compared to Hanks' Balanced Salt Solution, which was due to the aggressive nature of chloride ions and the inability 
of the pores in the coatings to adequately block the diffusion of the ions.

\section{ACKNOWLEDGMENTS}

The authors acknowledge the financial support of the Engineering Research Center for Revolutionizing Metallic Biomaterials (NSF EEC 0812348) for their financial support and the Center for Advanced Materials and Smart Structures at North Carolina A\&T State University for access to the necessary laboratory facilities and equipment.

\section{REFERENCES}

1.Yun, Y., et al., Biodegradable Mg corrosion and osteoblast cell culture studies. Materials Science \& Engineering C-Materials for Biological Applications, 2009. 29(6): p. 1814-1821.

2.Mitsuo, N., Recent research and development in titanium alloys for biomedical applications and healthcare goods. Science and Technology of Advanced Materials, 2003. 4(5): p. 445.

3. Manivasagam, G., D. Dhinasekara, and A. Rajamanickam, Biomedical Implants: Corrosion and its Prevention - A Review. Recent Patents on Corrosion Science, 2010(2): p. 15.

4.Braceras, I., et al., Bone cell adhesion on ion implanted titanium alloys. Surface and Coatings Technology, 2005. 196(1-3): p. 321-326.

5. Hanawa, T., In vivo metallic biomaterials and surface modification. Materials Science and Engineering: A, 1999. 267(2): p. 260-266.

6.Castellani, C., et al., Bone-implant interface strength and osseointegration: Biodegradable magnesium alloy versus standard titanium control. Acta Biomater., 2011. 7(Copyright (C) 2011 American Chemical Society (ACS). All Rights Reserved.): p. 432-440.

7.Park, J.B. and J.D. Bronzino, Biomaterials: Principles and Applications. 2002: CRC Press.

8. Staiger, M.P., et al., Magnesium and its alloys as orthopedic biomaterials: a review. Biomaterials, 2006. 27(9): p. 1728-34.

9. Witte, F., The history of biodegradable magnesium implants: a review. Acta Biomaterialia, 2010. 6(5): p. $1680-92$.

10. Bostman, O.M., Osteolytic changes accompanying degradation of absorbable fracture fixation implants. J Bone Joint Surg Br, 1991. 73(4): p. 679-82.

11. Dearnley, P.A., A brief review of test methodologies for surface-engineered biomedical implant alloys. Surface and Coatings Technology, 2005. 198(1-3): p. 483-490.

12. Vormann, J., Magnesium: nutrition and metabolism. Mol Aspects Med, 2003. 24(1-3): p. 27-37. 
13. Zeng, R., et al., Progress and Challenge for Magnesium Alloys as Biomaterials. Advanced Engineering Materials, 2008. 10(8): p. B3-B14.

14. Witte, F., et al., Degradable biomaterials based on magnesium corrosion. Current Opinion in Solid State \& Materials Science, 2008. 12(5-6): p. 63-72.

15. Kotoka, R., et al., Application of magnesium oxide functional coating for controlling the corrosion of magnesium for implant Applications, in ASME 2012 International Mechanical Congress \& Exposition Conference Proceedings. 2012, ASME: Houston, Texas.

16. Petrie, T.A., et al., Simple application of fibronectin-mimetic coating enhances osseointegration of titanium implants. J Cell Mol Med, 2009. 13(8B): p. 2602-12.

17. Witte, F., et al., In vivo corrosion of four magnesium alloys and the associated bone response. Biomaterials, 2005. 26(17): p. 3557-3563.

18. Zhang, S., et al., Research on an Mg-Zn alloy as a degradable biomaterial. Acta Biomaterialia, 2010. 6(2): p. 626-640.

19. Matl, F.D., et al., New anti-infective coatings of medical implants. Antimicrob Agents Chemother, 2008. 52(6): p. 1957-63.

20. Tonetti, M.S. and J. Schmid, Pathogenesis of implant failures. Periodontology 2000, 1994. 4(1): p. 127-138.

21. Kim, H.W., et al., On the feasibility of phosphate glass and hydroxyapatite engineered coating on titanium. Journal of Biomedical Materials Research Part A, 2005. 75A(3): p. 656-667.

22. Harada, Y., et al., Differential effects of different forms of hydroxyapatite and hydroxyapatite tricalcium phosphate particulates on human monocyte macrophages in vitro. Journal of Biomedical Materials Research, 1996. 31(1): p. 19-26.

23. Siebers, M.C., et al., Osteoclastic resorption of calcium phosphate coatings applied with electrostatic spray deposition (ESD), in vitro. Journal of Biomedical Materials Research Part A, 2005. 74A(4): p. $570-580$.

24. Daculsi, G., Biphasic calcium phosphate concept applied to artificial bone, implant coating and injectable bone substitute. Biomaterials, 1998. 19(16): p. 1473-1478.

25. Zhang, Y., G. Zhang, and M. Wei, Controlling the biodegradation rate of magnesium using biomimetic apatite coating. J Biomed Mater Res B Appl Biomater, 2009. 89(2): p. 408-14.

26. Song, Y.W., D.Y. Shan, and E.H. Han, Electrodeposition of hydroxyapatite coating on AZ91D magnesium alloy for biomaterial application. Materials Letters, 2008. 62(17-18): p. 3276-3279.

27. Zhai, Q., et al., Copper induces apoptosis in BA/F3 $\beta$ cells: Bax, reactive oxygen species, and NFkB are involved. Journal of Cellular Physiology, 2000. 184(2): p. 161-170. 
28. Schierholz, J.M., et al., Efficacy of silver-coated medical devices. Journal of Hospital Infection, 1998. 40(4): p. 257-262.

29. Song, W.H., H.S. Ryu, and S.H. Hong, Antibacterial properties of Ag (or Pt)-containing calcium phosphate coating formed by micro-arc oxidation. Journal of Biomedical Materials Research Part A, 2009. 88A(1): p. 246-254.

30. Singh, S.S., et al., A study of strontium doped calcium phosphate coatings on AZ31. Materials Science \& Engineering C-Materials for Biological Applications, 2014. 40: p. 357-365.

31. Chen, Z.T., et al., Osteoimmunomodulatory properties of magnesium scaffolds coated with betatricalcium phosphate. Biomaterials, 2014. 35(30): p. 8553-8565.

32. Chai, H.W., et al., In vitro and in vivo evaluations on osteogenesis and biodegradability of a sstricalcium phosphate coated magnesium alloy. Journal of Biomedical Materials Research Part A, 2012. 100A(2): p. 293-304.

33. Bakhsheshi-Rad, H.R., et al., Microstructure and bio-corrosion behavior of $\mathrm{Mg}-\mathrm{Zn}$ and $\mathrm{Mg}-\mathrm{Zn}-\mathrm{Ca}$ alloys for biomedical applications. Materials and Corrosion, 2014. 65(12): p. 1178-1187.

34. Creus, J., H. Mazille, and H. Idrissi, Porosity evaluation of protective coatings onto steel, through electrochemical techniques. Surface and Coatings Technology, 2000. 130(2-3): p. 224-232.

35. Witek, L., et al., Sintering effects on chemical and physical properties of bioactive ceramics. Journal of Advanced Ceramics, 2013. 2(3): p. 274-284.

36. Carrodeguas, R.G. and S. De Aza, $\alpha$-Tricalcium phosphate: Synthesis, properties and biomedical applications. Acta Biomaterialia, 2011. 7(10): p. 3536-3546.

37. Carbajal, L., et al., Role of $\mathrm{ZnO}$ additions on the beta/alpha phase relation in TCP based materials: Phase stability, properties, dissolution and biological response. Journal of the European Ceramic Society, 2014. 34(5): p. 1375-1385.

38. Torigoe, I., et al., Bone Regeneration with Autologous Plasma, Bone Marrow Stromal Cells, and Porous beta-Tricalcium Phosphate in Nonhuman Primates. Tissue Engineering Part A, 2009. 15(7): p. 1489-1499.

39. Kotani, S., et al., Bone Bonding Mechanism of Beta-Tricalcium Phosphate. Journal of Biomedical Materials Research, 1991.25(10): p. 1303-1315.

40. Banerjee, S.S., et al., Understanding the influence of $\mathrm{MgO}$ and $\mathrm{SrO}$ binary doping on the mechanical and biological properties of beta-TCP ceramics. Acta Biomaterialia, 2010. 6(10): p. 4167-4174.

41. Mroz, W., et al., Characterization of calcium phosphate coatings doped with Mg, deposited by pulsed laser deposition technique using ArF excimer laser. Micron, 2009. 40(1): p. 140-142. 
42. Zeng, H., W.R. Lacefield, and S. Mirov, Structural and morphological study of pulsed laser deposited calcium phosphate bioceramic coatings: Influence of deposition conditions, laser parameters, and target properties. Journal of Biomedical Materials Research, 2000. 50(2): p. 248-258.

43. Prem Ananth, K., et al., Structural and chemical analysis of silica-doped $\beta$-TCP ceramic coatings on surgical grade 316L SS for possible biomedical application. Journal of Asian Ceramic Societies, 2015. 3(3): p. 317-324.

44. Shadanbaz, S. and G.J. Dias, Calcium phosphate coatings on magnesium alloys for biomedical applications: A review. Acta Biomaterialia, 2012. 8(1): p. 20-30.

45. Hesaraki, S., M. Safari, and M.A. Shokrgozar, Development of beta-tricalcium Phosphate/Sol-Gel Derived Bioactive Glass Composites: Physical, Mechanical, and In Vitro Biological Evaluations. Journal of Biomedical Materials Research Part B-Applied Biomaterials, 2009. 91B(1): p. 459469.

46. Liu, S., et al., Preparation and Antibacterial Activities of Porous Silver-Doped beta-Tricalcium Phosphate Bioceramics. International Journal of Applied Ceramic Technology, 2015. 12(2): p. 294-299.

47. Song, G. and A. Atrens, Understanding Magnesium Corrosion-A Framework for Improved Alloy Performance. Advanced Engineering Materials, 2003. 5(12): p. 837-858.

48. Kotoka, R., et al., Corrosion Behavior of Reactive Sputtered A12O3 and ZrO2 Thin Films on Mg Disk Immersed in Saline Solution. Journal of Materials Science \& Technology, 2015. 31(9): p. 873880.

49. Waizy, H., et al., In vitro corrosion of ZEK100 plates in Hank's Balanced Salt Solution. BioMedical Engineering OnLine, 2012. 11: p. 12-12.

50. Jang, Y., et al., Effect of biologically relevant ions on the corrosion products formed on alloy AZ31B: An improved understanding of magnesium corrosion. Acta Biomaterialia, 2013. 9(10): p. 87618770 .

51. Abdel Aal, A., Protective coating for magnesium alloy. Journal of Materials Science, 2008. 43(8): p. 2947-2954.

52. Ahn, S.H., et al., A study on the quantitative determination of through-coating porosity in PVD-grown coatings. Applied Surface Science, 2004. 233(1-4): p. 105-114. 


\section{List of figures and Tables}

Fig. 1. (a) XRD pattern for sintered $\beta$-TCP doped with different compositions of Ag targets and (b) XRD pattern for sintered pure $\beta$-TCP target and pure $\beta$-TCP coating on Mg substrate

Fig. 2. SEM micrograph of (a) pure Mg, $\beta$-TCP dope with (b) 0 wt. \%, (c) 1 wt. \% (d) 5 wt. \% and (e) 10 wt. $\%$ Ag coatings on $\mathrm{Mg}$

Fig. 3. Cross-section SEM micrograph of $\beta$-TCP dope with (a) 0 wt. \%, (b) 1 wt. \% (c) 5 wt. \% and (d) 10 wt. $\%$ Ag coatings on $\mathrm{Mg}$

Fig. 4. DC polarization curves of the uncoated and coated Mg samples immersed in (a) Hanks' Balanced Salt Solution and (b) physiological saline solution for $2 \mathrm{~h}$

Fig. 5. Protection efficiency of TCP doped with different concentrations of Ag immersed in Hanks' Balanced Salt Solution for $24 \mathrm{~h}$

Fig. 6. EIS results of uncoated and coated Mg samples immersed in (a) Hanks' Balanced Salt Solution and (b) physiological saline solution for $2 \mathrm{~h}$

Fig. 7. Equivalent circuit for modeling corrosion data (a) bare magnesium and (b) coated magnesium

Fig. 8. Polarization resistance of Mg in Hanks' Balanced Salt Solution and physiological saline solution

Fig. 9. Porosity of coated Mg samples immersed in (a) Hanks' Balanced Salt Solution and (b) physiological saline solution for $24 \mathrm{~h}$

Fig. 10. SEM micrograph of (a) pure Mg and $\beta$-TCP dope with (b) 0 wt. \%, (c) 1 wt. \% (d) 5 wt. $\%$ and (e) $10 \mathrm{wt}$. \% Ag coatings on $\mathrm{Mg}$ after $24 \mathrm{hr}$ corrosion in saline solution

Fig. 11. $\mu \mathrm{XRF}$ mapping of pure TCP coating on Mg substrate immersed in physiological saline solution after $24 \mathrm{~h}$

Table 1 Elemental analysis of sintered TCP target

Table 2 Elemental analysis of TCP coatings developed on Mg substrate

Table 3 Some important parameters obtained from polarization measurements 

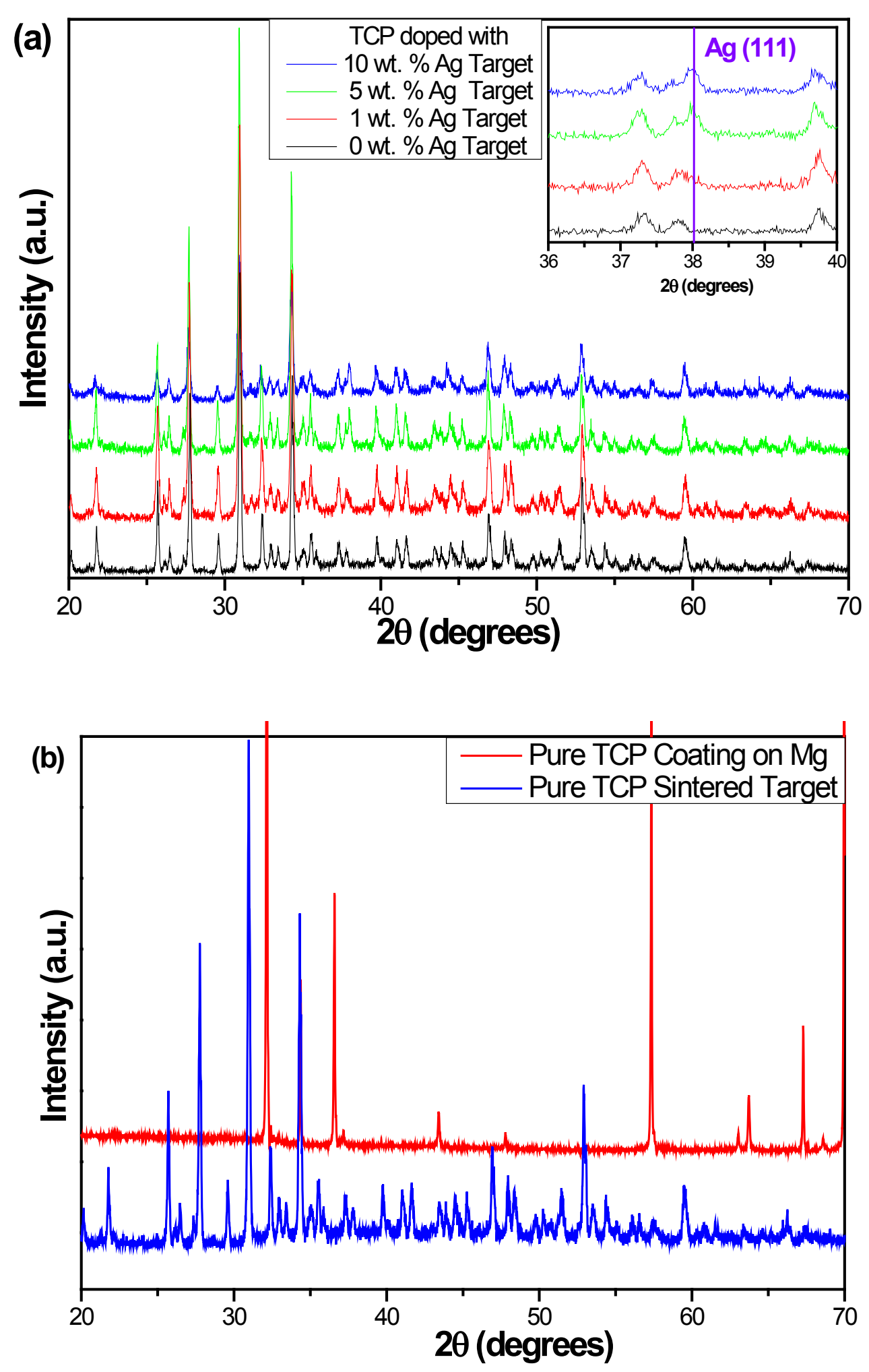

Fig. 1. 

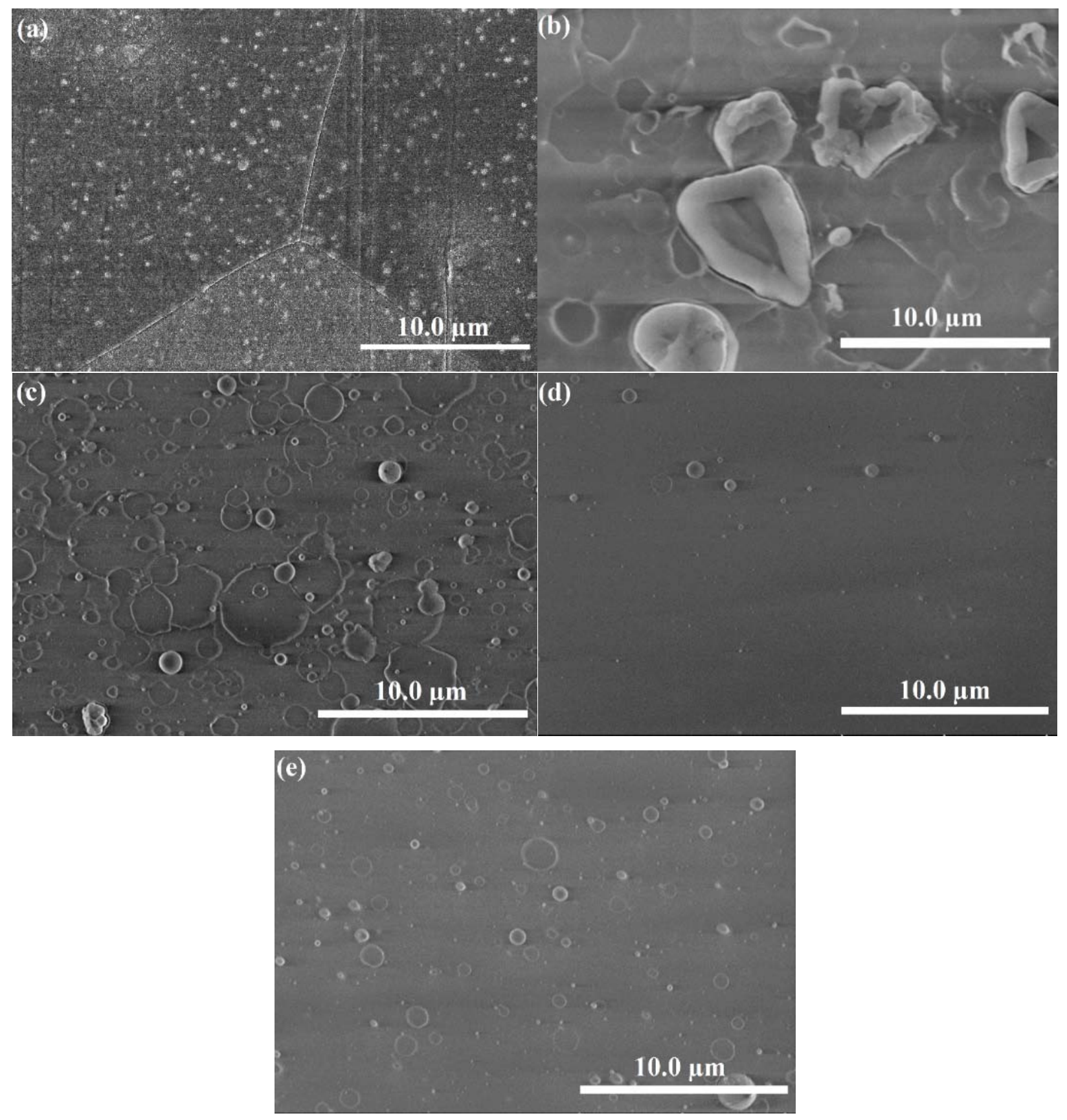

Fig. 2. 

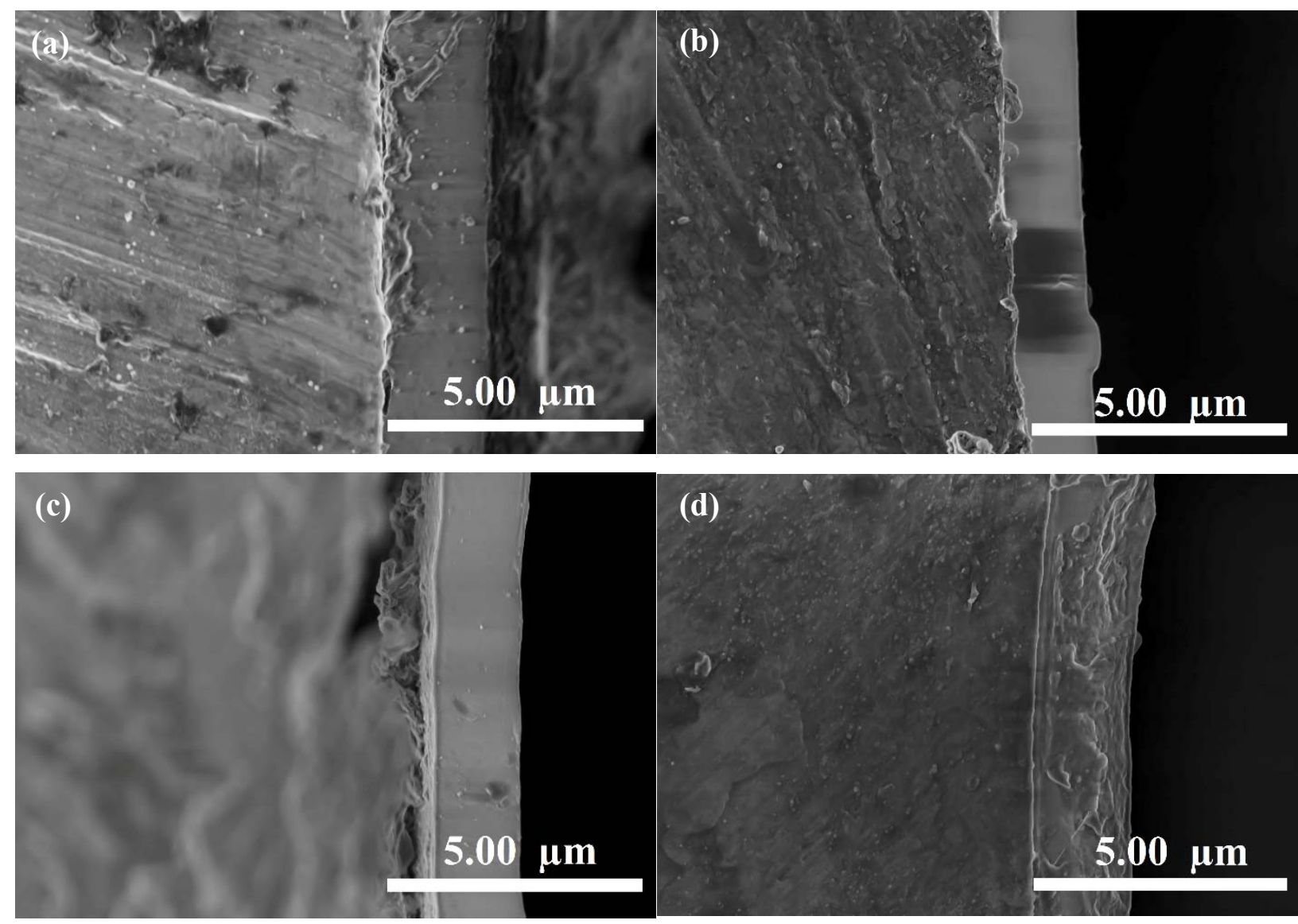

Fig. 3. 

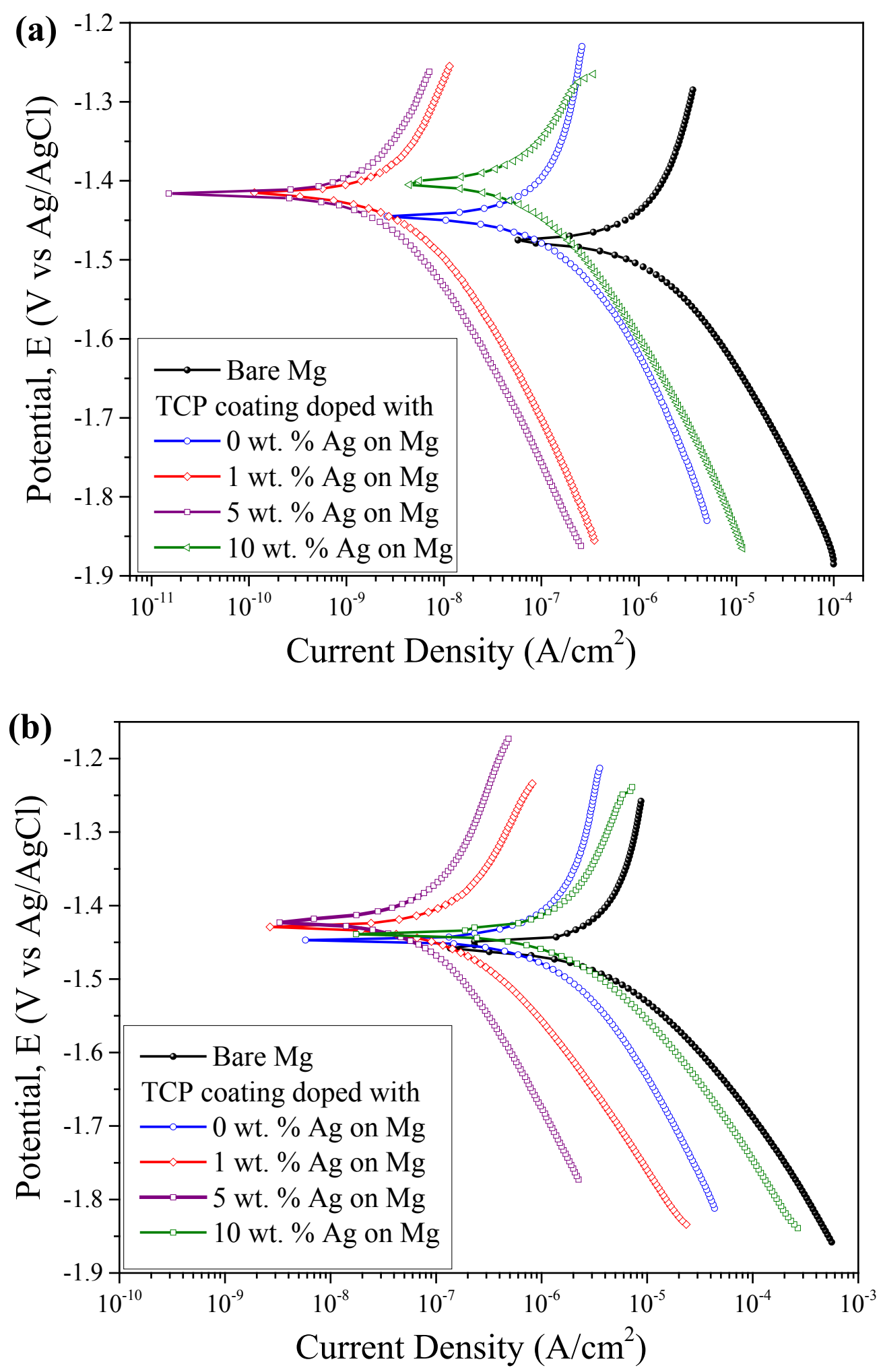

Fig. 4. 


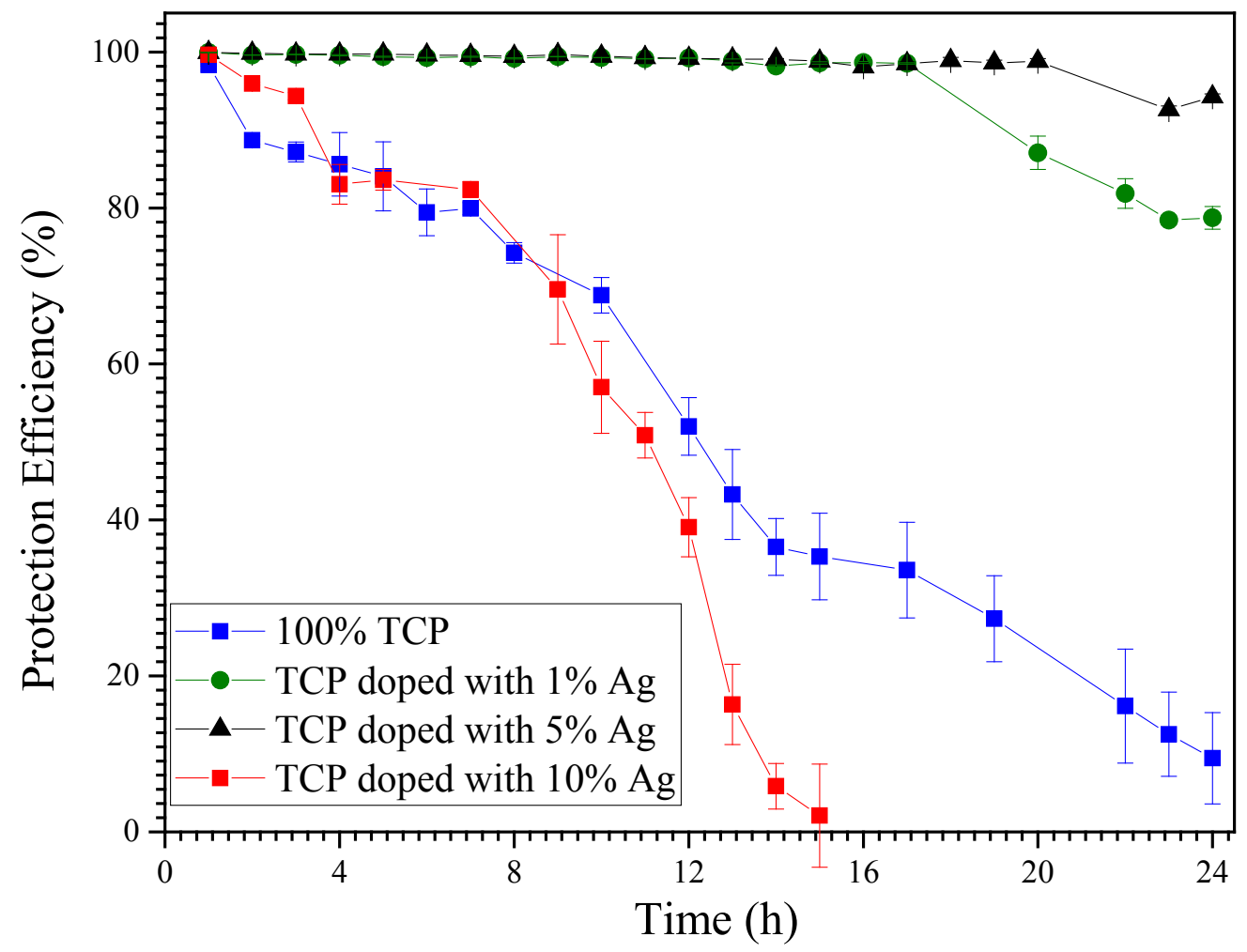

Fig. 5. 

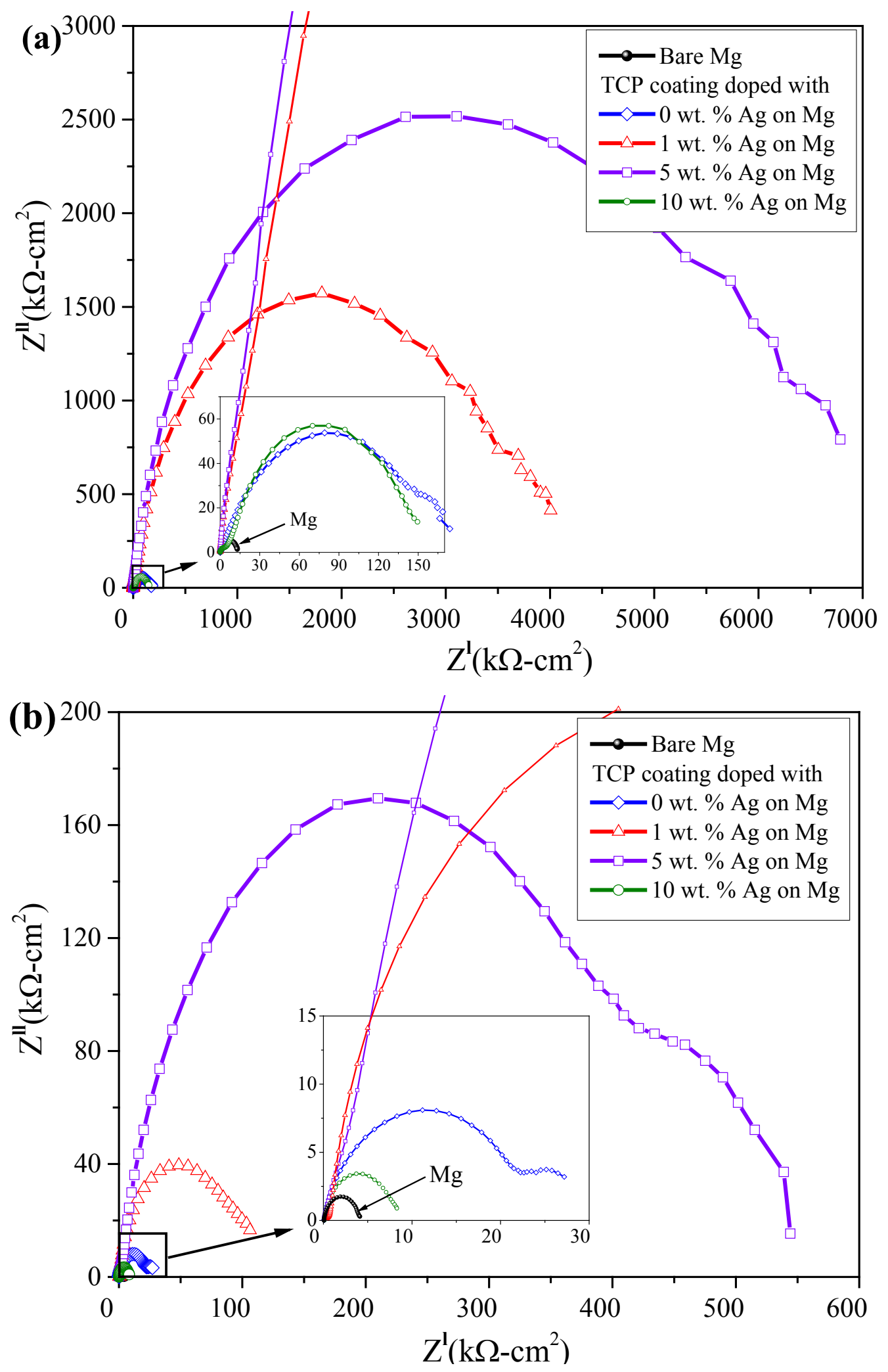

Fig. 6. 

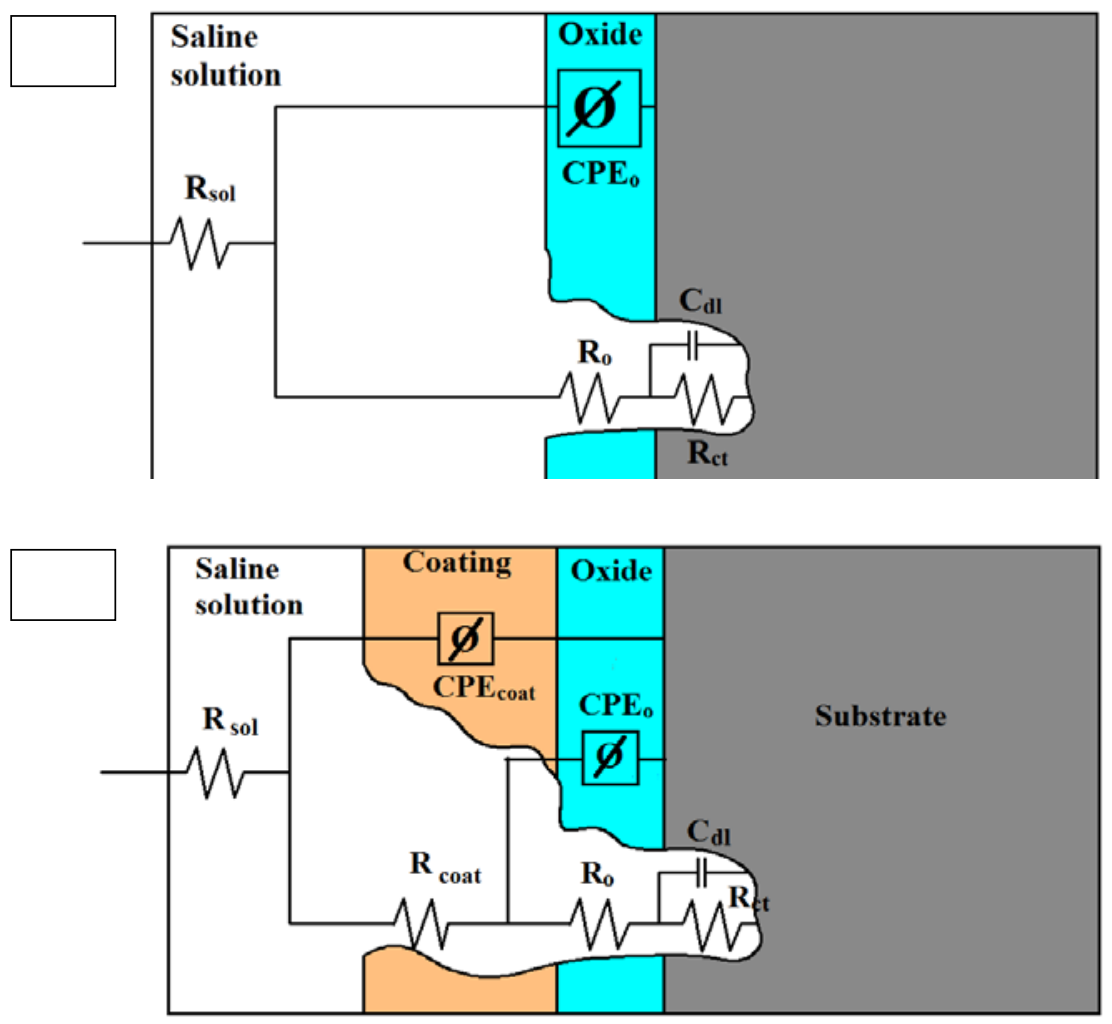

Fig. 7.

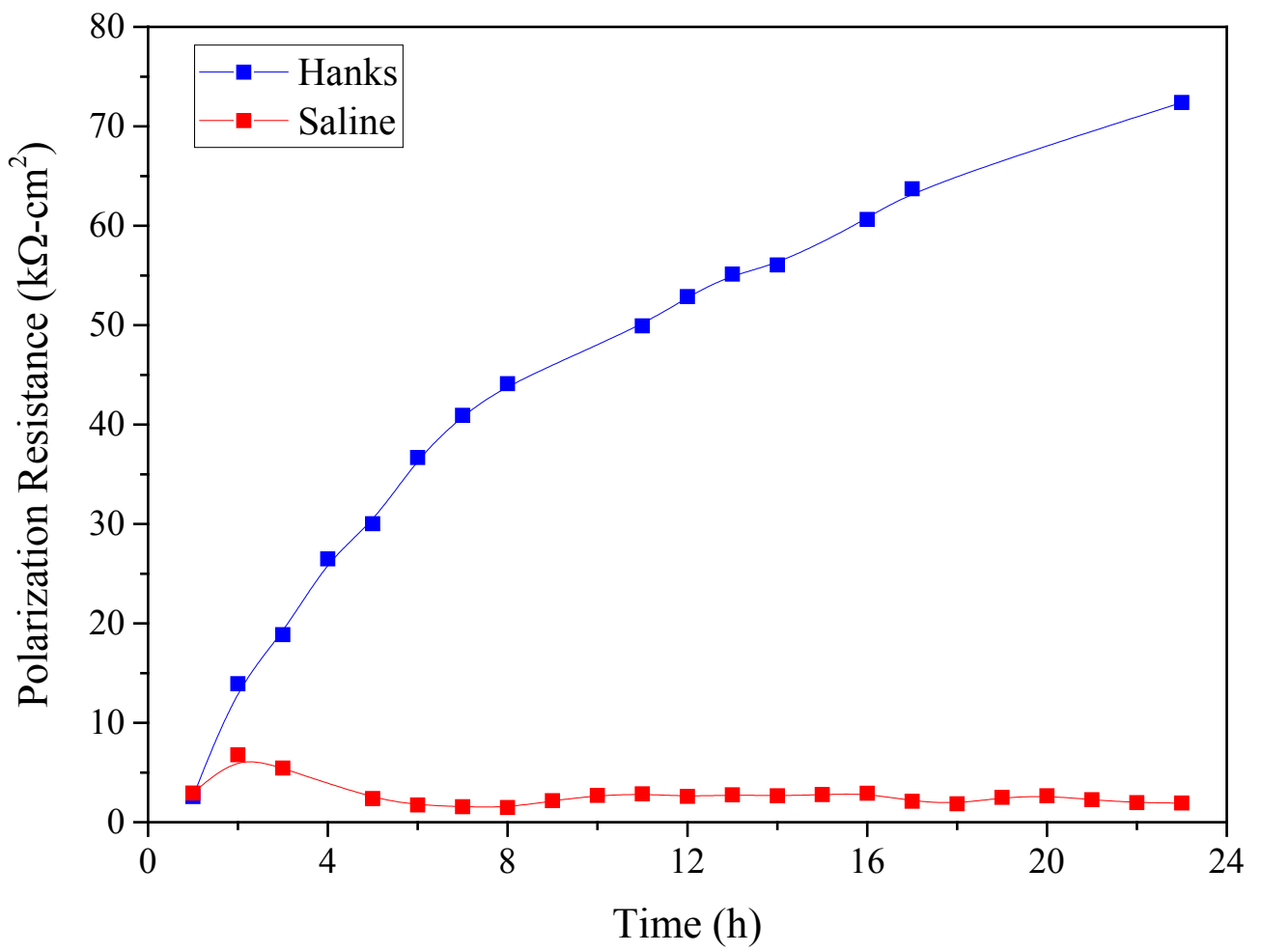

Fig. 8. 

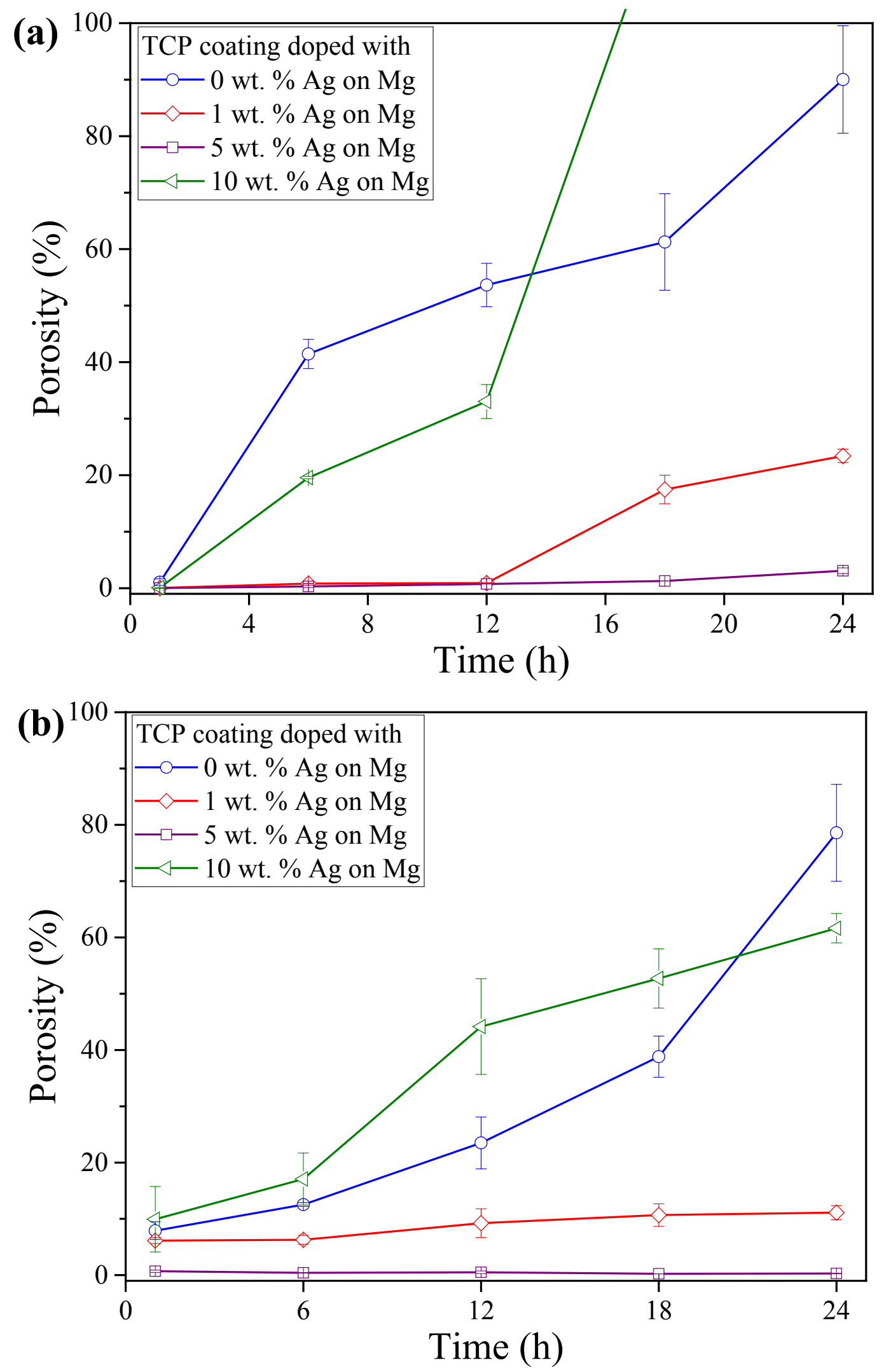

Fig. 9. 

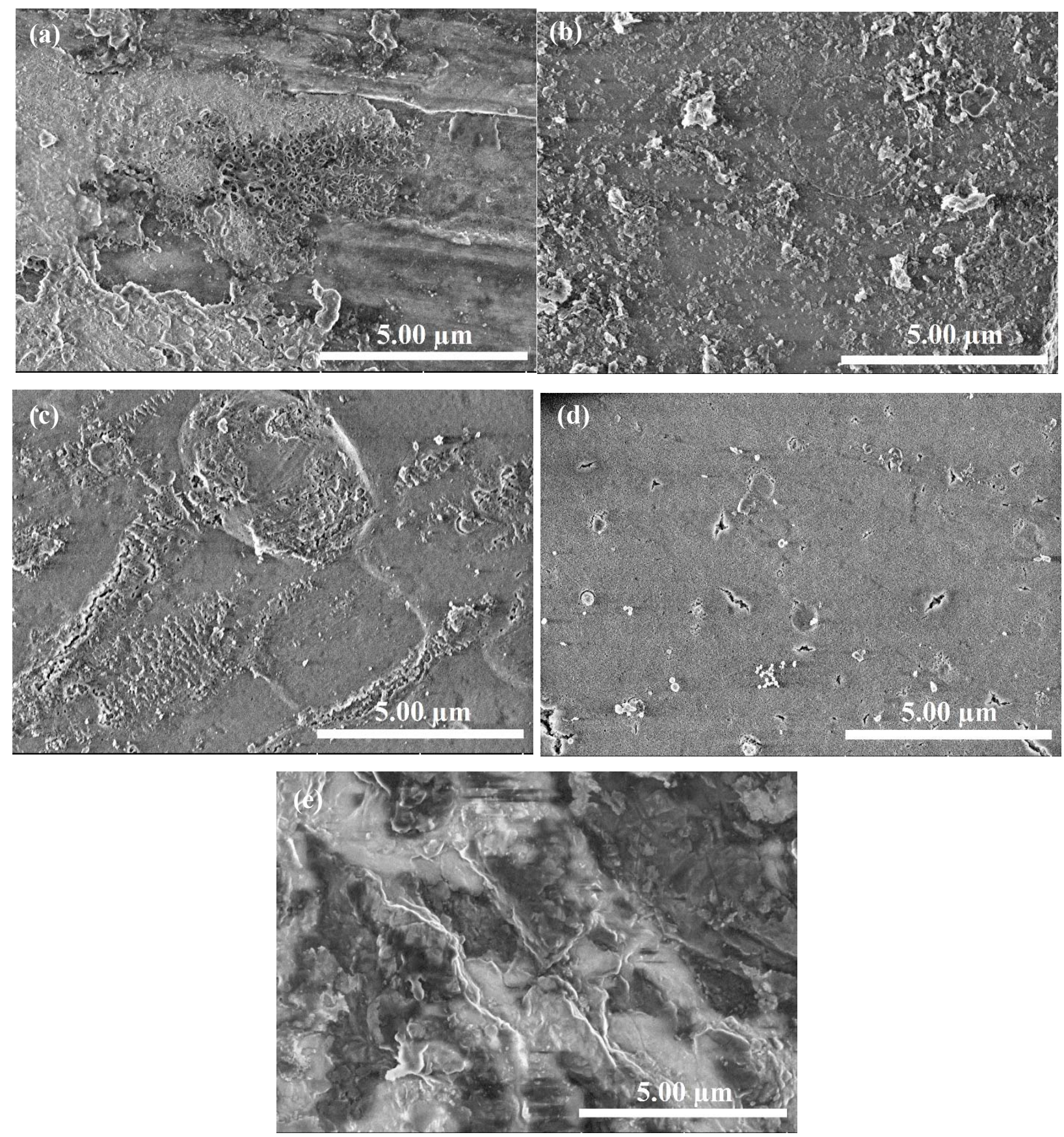

Fig. 10. 


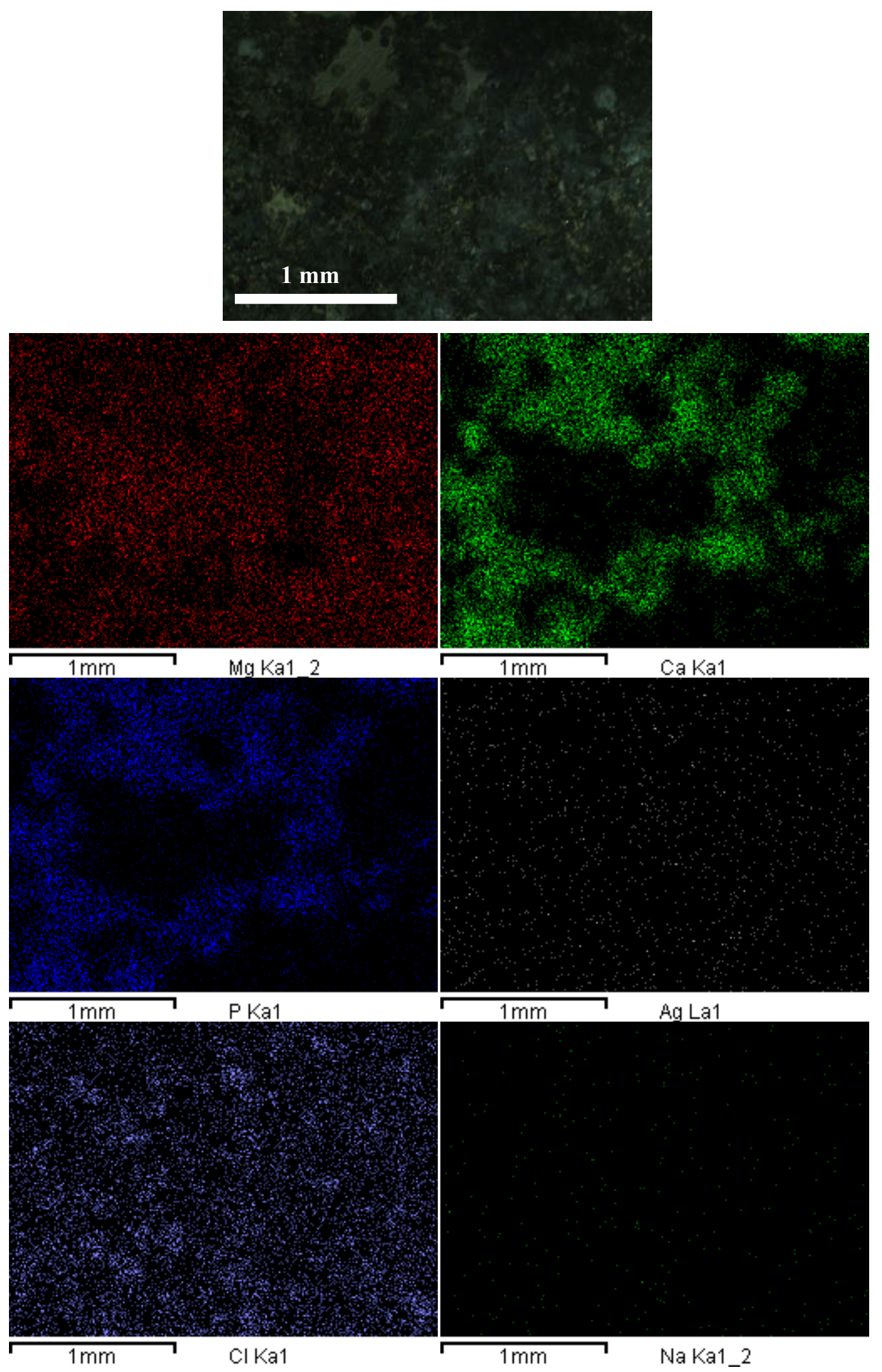




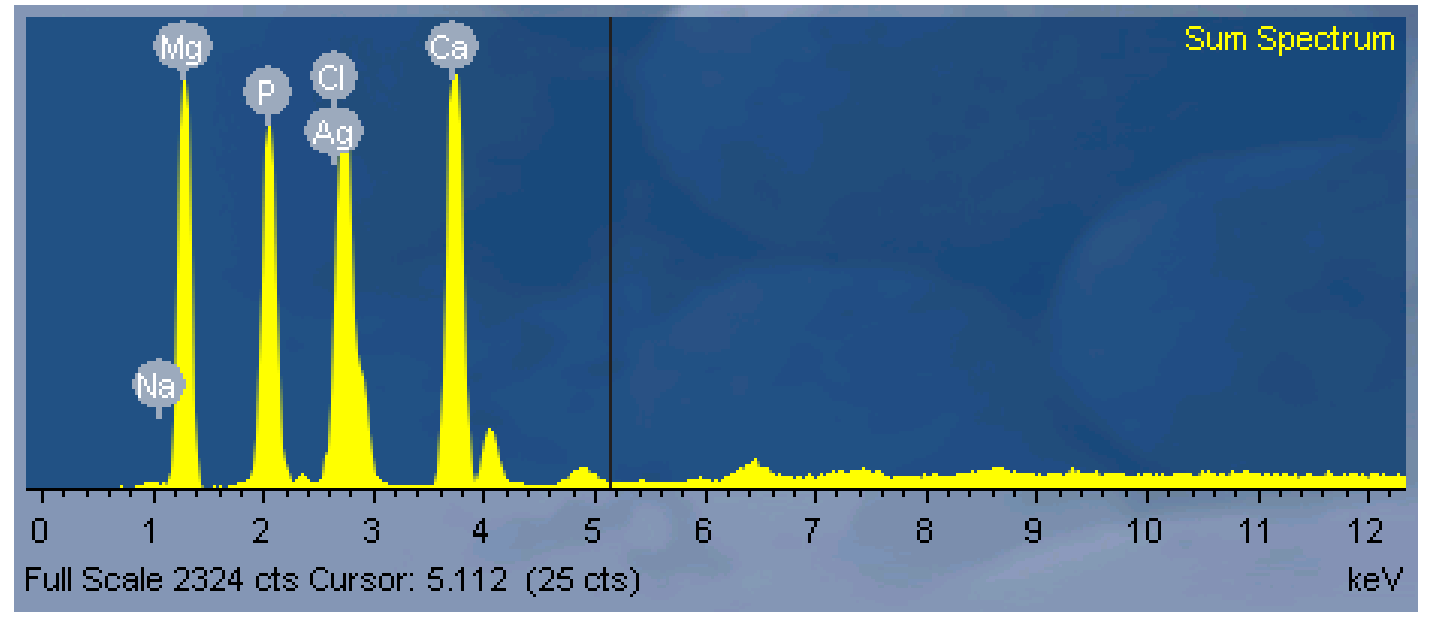

Fig. 11 
Table 1

Elemental analysis of TCP sintered target

\begin{tabular}{lcccccc}
\hline & \multicolumn{3}{c}{ Atomic (\%) } & \multicolumn{2}{c}{ Mass (\%) } \\
Sample & $\mathrm{Ca}$ & $\mathrm{P}$ & $\mathrm{Ag}$ & $\mathrm{Ca}$ & $\mathrm{P}$ & $\mathrm{Ag}$ \\
\hline TCP + 0 wt. \% Ag & $59.68 \pm 0.53$ & $40.32 \pm 0.53$ & - & $65.70 \pm 0.50$ & $34.30 \pm 0.50$ & - \\
TCP + 1 wt. \% Ag & $60.65 \pm 0.78$ & $39.19 \pm 0.78$ & $0.16 \pm 0.03$ & $66.38 \pm 0.73$ & $33.16 \pm 0.73$ & $0.96 \pm 0.03$ \\
TCP + 5 wt. \% Ag & $55.09 \pm 0.26$ & $42.10 \pm 0.26$ & $2.81 \pm 0.25$ & $57.88 \pm 0.42$ & $34.18 \pm 0.40$ & $7.92 \pm 0.68$ \\
TCP +10 wt. \% Ag & $53.57 \pm 0.24$ & $42.76 \pm 0.27$ & $3.66 \pm 0.24$ & $55.53 \pm 0.26$ & $34.25 \pm 0.37$ & $10.22 \pm 0.61$ \\
\hline
\end{tabular}

Table 2

Elemental analysis of TCP coatings developed on Mg substrate

\begin{tabular}{lcccccc}
\hline & \multicolumn{3}{c}{ Atomic (\%) } & \multicolumn{3}{c}{ Mass (\%) } \\
Sample & $\mathrm{Ca}$ & $\mathrm{P}$ & $\mathrm{Ag}$ & $\mathrm{Ca}$ & $\mathrm{P}$ & $\mathrm{Ag}$ \\
\hline TCP + 0 wt. \% Ag & $62.19 \pm 2.43$ & $37.89 \pm 2.43$ & - & $68.02 \pm 2.23$ & $37.89 \pm 2.23$ & - \\
TCP + 1 wt. \% Ag & $61.01 \pm 1.85$ & $38.79 \pm 1.87$ & $0.19 \pm 0.07$ & $66.66 \pm 1.69$ & $32.76 \pm 1.76$ & $0.58 \pm 0.19$ \\
TCP + 5 wt. \% Ag & $59.84 \pm 0.14$ & $38.34 \pm 0.19$ & $2.09 \pm 0.07$ & $65.64 \pm 0.12$ & $32.36 \pm 0.19$ & $5.89 \pm 0.20$ \\
TCP +10 wt. \% Ag & $56.95 \pm 1.17$ & $39.48 \pm 1.42$ & $3.57 \pm 0.51$ & $58.67 \pm 1.03$ & $31.43 \pm 1.42$ & $9.90 \pm 1.31$ \\
\hline
\end{tabular}

Table 3

Some important parameters obtained from polarization measurements

\begin{tabular}{lcccccc}
\hline & \multicolumn{3}{c}{ Hanks' Balance Salt Solution } & \multicolumn{3}{c}{$0.9 \%$ wt NaCl solution } \\
Sample & Ecorr & Icorr & $\mathrm{R}_{\mathrm{p}}$ & Ecorr & Icorr & $\mathrm{R}_{\mathrm{p}}$ \\
& $(\mathrm{mV})$ & $\left(\mu \mathrm{A} / \mathrm{cm}^{2}\right)$ & $\mathrm{M} \Omega$ & $(\mathrm{mV})$ & $\left(\mu \mathrm{A} / \mathrm{cm}^{2}\right)$ & $\mathrm{M} \Omega$ \\
\hline Mg substrate & -148 & $2.60 \pm 0.63$ & $0.03 \pm 0.00$ & -146 & $5.10 \pm 0.57$ & $0.01+0.00$ \\
TCP +0 wt. $\% \mathrm{Ag}$ & -147 & $0.35 \pm 0.02$ & $0.36 \pm 0.00$ & -145 & $3.57 \pm 0.85$ & $0.04 \pm 0.00$ \\
TCP +1 wt. $\% \mathrm{Ag}$ & -143 & $0.01 \pm 0.00$ & $9.68 \pm 0.05$ & -143 & $0.28 \pm 0.01$ & $0.23 \pm 0.00$ \\
TCP +5 wt. $\% \mathrm{Ag}$ & -143 & $0.01 \pm 0.00$ & $11.94 \pm 1.25$ & -143 & $0.18 \pm 0.05$ & $0.90 \pm 0.02$ \\
TCP +10 wt. $\% \mathrm{Ag}$ & -140 & $0.13 \pm 0.01$ & $0.50 \pm 0.00$ & -144 & $2.46 \pm 0.13$ & $0.02 \pm 0.01$ \\
\hline
\end{tabular}

